INVESTIGACIÓN/RESEARCH

\title{
CONSUMO DEL ENOTURISMO EN LA D.O. RIBERA DEL DUERO
}

Mónica Matellanes-Lazo1: Universidad Europea Miguel de Cervantes de Valladolid. España. $\underline{\text { mmatellanes@uemc.es }}$

\section{RESUMEN}

En los últimos años, la palabra enoturismo, se ha incorporado definitivamente a nuestro vocabulario. Se trata de una nueva forma de turismo temático de carácter rural y con el vino como eje fundamental. En líneas generales, por enoturistas se entiende a las personas aficionadas al vino (no profesionales) que tienen un interés cultural hacia este producto y aprovechan vacaciones o tiempo libre para conocer zonas vitivinícolas, visitar bodegas, aprender los procesos de la elaboración e incluso vivir cerca la experiencia de la vendimia. La investigación que se muestra tiene por objetivo conocer el perfil del turista del vino en la D.O. Ribera del Duero y conocer sus gustos y preferencias de consumo del enoturismo. Para ello se ha realizado un cuestionario descriptivo para la obtención de los objetivos marcados. Los resultados aportan en crecimiento de las visitas a las bodegas de la D.O. Ribera del Duero y la preferencia por las catas y comidas en bodega.

PALABRAS CLAVE: Enoturismo - D.O. Ribera del Duero - Consumo - Coste Servicios - Turistas.

\footnotetext{
${ }^{1}$ Autor correspondiente:

Mónica Matellanes-Lazo: Profesora Doctora Agregada de la Universidad Europea Miguel de Cervantes de Valladolid (España). Experta en Marketing y Comunicación del Enoturismo.

Correo: mmatellanes@uemc.es
} 


\title{
ENOLOGICAL TOURISM CONSUME IN D.O. RIBERA DEL DUERO
}

\begin{abstract}
In the last few years, the composed word enological-tourism has become a part of our vocabulary. It is a new and rural type of thematic tourism with wine as its turning point. In general, we understand that enology-tourists are people who are wine lovers who have a cultural interest in this product and take advantage of holidays or free time to get to know wine regions, visit wineries, learn about the elaboration proccess and even closely live the grape harvest experience. The research pretends to show the wine sector and enological-tourism to many people with a spectacular and interactive way. It pretends to know what is the opinion and perfile of the tourists. With several questionnaires made to the tourists of Ribera del Duero, we will obtain a current viewpoint of enological-tourism in Ribera del Duero and preferences of the tourists' perfile in this region of Spain.
\end{abstract}

KEY WORDS: Enological-tourism - D.O. Ribera del Duero - Consume - Cost Services - Tourists.

\section{INTRODUCCIÓN}

La historia de los vinos de Castilla y León está íntimamente ligada a la historia de la comunidad. Su origen se remonta a la antigüedad, incluso antes de la era cristiana, cuando ya existían plantaciones en las comarcas zamoranas. La llegada del Imperio Romano propició su cultivo y su comercio. Pero no es hasta la Edad Media, con el descubrimiento del sepulcro del apóstol Santiago en Compostela y la consiguiente puesta en escena del Camino de Santiago, cuando se desarrollan las repoblaciones vitivinícolas paralelas a la expansión de los reinos cristianos y ubicados alrededor de monasterios y grandes fortalezas. Los monjes franceses de Cluny y del Císter acercaron a España técnicas de elaboración y cultivo de la vid, desarrolladas con éxito en Francia, de tal forma que el vino español adquirió fuerza en toda Europa.

Gracias a las ferias de Medina del Campo, los vinos castellanos y leoneses experimentan un crecimiento importante y poco a poco se convierten en el eje económico de la región, llegando a ser muy cotizados en todo el territorio nacional. Con el traslado de la Corte a Madrid, que hasta entonces había permanecido en Valladolid, se pierde cierto peso a pesar de poder leer líneas como las que escribió Quevedo: "Que más abriga una bota de Alaejos que todos los paños de Flandes".

Con la llegada de los Borbones, los tradicionales vinos blancos castellanos se tiñen con el objetivo de asemejarse a los "Clairet" y a los "Rouge" de Francia. Así es como surgen los claretes y los tintos, gracias al mecanismo de tintar a través de uvas rojas a los vinos blancos. 
En 1898 una epidemia de filoxera arrasó los viñedos de Castilla y León. Los viticultores castellanos y leoneses, con el nuevo siglo, lograron dotar de personalidad propia y más carácter a los caldos de la región.

Es importante tener en cuenta las características geográficas, geológicas y climáticas de las comarcas para definir cada uno de los caldos de la comunidad. Desde Peñafiel hasta Rueda el salto enológico es similar al que se origina desde Jerez a Burdeos.

Uno de los valores añadidos lo constituye el río Duero. En su recorrido hasta Portugal este río "mima" con su agua los vinos que se desarrollan en sus orillas como los de las Denominaciones de Origen de Rueda, Toro, Vino de la Tierra, Cigales y Ribera del Duero. Sin olvidar el resto de asociaciones y agrupaciones de vinos de la tierra y vinos de calidad. La experiencia de otra zonas vinícolas en las que el enoturismo es un excelente modo de dar a conocer los vinos en el entorno en el que se elaboran, puede servir de ejemplo a Castilla y León, que cuenta con los ingredientes necesarios para impulsar esta nueva forma de entender la cultura del vino.

\subsection{La D.O. Ribera del Duero.}

Desde 1975 ya se comenzó a hablar del gran potencial que poseían los vinos de la Ribera. El reconocimiento provisional de la Denominación de Origen fue en 1979, pero no fue aprobada hasta el 21 de julio de 1982. Desde ese momento, se trabajó por elevar y mantener la calidad y el reconocimiento tanto nacional como internacional de los caldos de la región.

Cuenta en la actualidad con más de veinte mil hectáreas de viñedos. Éstos están localizados dentro de la cuenca del Duero, con una extensión de unos 115 kilómetros de longitud y 35 de anchura. Se extiende por las provincias de Burgos (80,5\%), siendo ésta la de mayor extensión, seguida de Valladolid (11,2\%), Soria (7,5\%) y Segovia $(0,8 \%)$. El Consejo Regulador de la D.O. se encuentra en Roa de Duero (Burgos). En la D.O. Ribera del Duero predominan los tintos, aunque también existen rosados. La principal variedad de uva de estos caldos es el Tempranillo, que aporta cuerpo, aroma y color a estos vinos y que constituye más del 90\% de la producción.

También existen otras variedades de uva permitidas por el Consejo, como son la Cabernet-Sauvignon, Merlot, Malbec, Garnacha y Albillo. Actualmente son 256 las bodegas $^{2}$ recogidas en el boletín oficial del Consejo Regulador de Ribera del Duero de 2007.

\footnotetext{
${ }^{2}$ Datos obtenidos por el Consejo Regulador Ribera del Duero el 7 de mayo de 2012, Roa de Duero Burgos. Para más información disponible en Internet en el link: http://www.riberadelduero.es/web/bodegas/bodegas.asp
} 


\subsection{Descripción Geográfica.}

En el mundo del vino de Castilla y León, la D.O. Ribera del Duero es la zona más importante cuantitativamente y cualitativamente. Su superficie total, próxima a los $3.000 \mathrm{~km}^{2}$, se reparte entre las cuatro provincias mencionadas anteriormente. Son aproximadamente 95.000 personas las que habitan la región, compuesta por numerosos y pequeños núcleos y algunas cabeceras de comarca. Tanto el número de hectáreas de viñedo (18.900 has ${ }^{3}$ ) como el de bodegas (256 elaboradoras), superan ampliamente a cualquier otra zona del Valle del Duero y de Castilla y León.

Las comunicaciones se limitan casi en exclusiva a las carreteras: la N-122 (futura A- II) atraviesa la comarca de este a oeste, mientras que la N-I, conecta Madrid con Burgos a través de núcleos como Aranda de Duero. El ferrocarril Madrid - Burgos sigue siendo un trazado paralelo a la N-I, aunque es menos utilizado.

\subsection{Riqueza Monumental.}

La zona vinícola pasa por ser la de mayor riqueza monumental y paisajística, con innumerables ejemplos destacados, que de este a oeste irían desde San Esteban de Gormaz, Langa de Duero, La Vid, Peñaranda de Duero, Aranda de Duero, Roa, Peñafiel, Valbuena y Olivares de Duero, entre otros, poseen en conjunto la colección de castillos, iglesias, monasterios y obras de arte más extensa de las comarcas vinícolas de la comunidad de Castilla y León. Entre el patrimonio vinculado al mundo de la Enología destacan el Museo del Vino de Peñafiel (Valladolid) instalado en un castillo ${ }^{4}$ y rehabilitado en varias ocasiones para tal fin, así como el conjunto de galerías y bodegas subterráneas de Aranda de Duero que junto al Centro de Interpretación ${ }^{5}$ de la Arquitectura del Vino (Ciavin), hacen de la villa arandina un núcleo de importante relevancia para conocer y tener un contacto más cercano con la cultura del vino.

\footnotetext{
${ }^{3}$ Como dato de interés en lo se refiere al número de hectáreas de viñedo, en 1857 sólo en la provincia de Burgos existían 43.000 hectáreas de viñedo.

${ }^{4}$ Declarado Monumento Nacional en 1917, es considerado como una de las más bellas fortificaciones del medievo, y se le ha comparado poéticamente con un inmenso barco. Su aspecto actual responde a diferentes construcciones entre finales del siglo IX o principios del X, se reestructura a finales del XI, Don Juan Manuel lo restaura en el siglo XIV, y nuevamente es construido a mediados del siglo XV.

${ }^{5}$ Para más información se puede consultar la página Web en Internet: www.arandacentrodelvino.com
} 


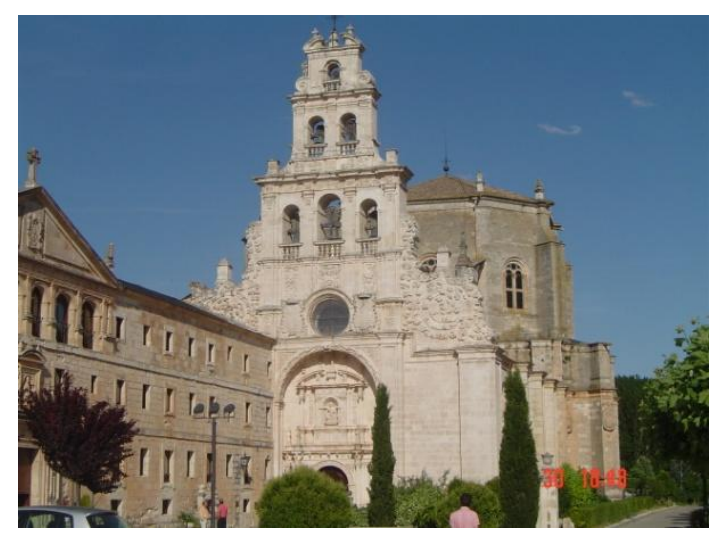

Foto 1. Fachada del Monasterio de La Vid - La Vid (Burgos).

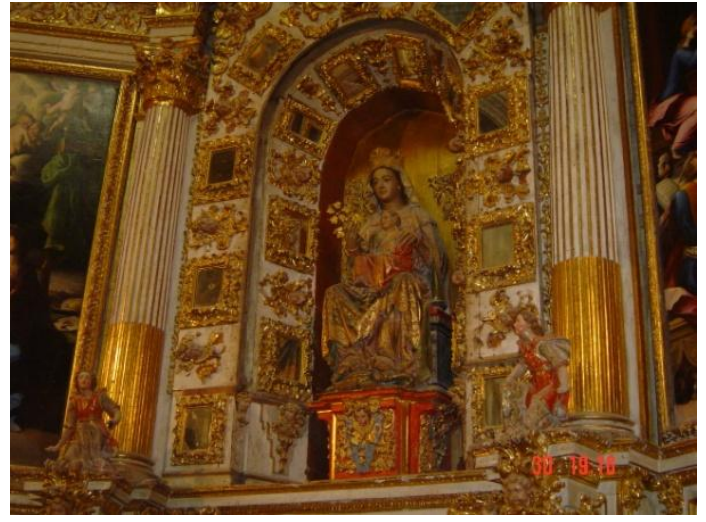

Foto 2. Virgen Gótica (s.XIII) de La Vid - Retablo de la Capilla del Monasterio de La Vid - La Vid (Burgos).

\subsection{Oferta Hostelera.}

La comarca tiene bien potenciada su oferta hotelera, con 82 alojamientos de distintos tipos (1.950 camas en total), entre los que destacan un cinco estrellas (Hotel Arzuaga Navarro, en Quintanilla de Onésimo provincia de Valladolid) y cuatro establecimientos de 4 estrellas (Torremilanos y Tudanca en Aranda de Duero, Hotel Convento las Claras en Peñafiel y Fuente la Aceña, de nuevo en Quintanilla). Todos ellos poseen una vinculación directa con el mundo del vino y algunos están promovidos por bodega de prestigio.

El número de restaurantes también es numeroso (140) y con una capacidad global considerable (11.542 plazas), con 2 locales de alta categoría, ambos en Quintanilla de Onésimo y otro recientemente edificado en el verano de 2006, como es el Hotel y Restaurante las Claras en Peñafiel (Valladolid).

En cuanto a la distribución geográfica, Aranda aglutina 15 alojamientos (699 camas), mientras que Peñafiel acoge a 7 empresas (290 plazas) en la capital Ribera vallisoletana. Los restaurantes se concentran en Aranda (45 locales para 2.950 comensales) con el 34\% de la oferta, Roa (8 establecimientos y 825 plazas), San Esteban de Gormaz (9 locales y 756 plazas) y Peñafiel (27 restaurantes y 2.053 plazas).

\subsection{Oferta Enoturística.}

Se sabe que Castilla y León es una de las comunidades más desarrolladas en temas relacionados con el vino, tanto es así, que en el año 2010 se creó un canal de vinos en esta comunidad, donde van apareciendo las diferentes actividades que se van desarrollando, así como, numerosas herramientas para que las personas interesadas puedan interactuar con este canal. No se ha de olvidar que el contacto a través de Internet es fundamental al igual que cuidar el sitio web de la bodega o empresa relacionada con el enoturismo (Gómez, 2006). 
Este canal nace con la intención de convertirse en un portal de referencia sobre los vinos de Castilla y León. El objetivo de este proyecto es acercar a la sociedad la cultura del vino y fomentar su consumo, a través de tres pilares fundamentales. Por un lado, se pretende ofrecer más información para transmitir la realidad del sector; por otro lado, se organizarán eventos relacionados con el vino, tanto dentro como fuera de Castilla y León; gracias a un nuevo vehículo de comunicación, el canal www.castillayleondevinos.com (Diputación Provincial de Valladolid, 2011).

La crisis económica ha producido un descenso del consumo de vinos a nivel mundial que afectó a los principales países productores, entre ellos España. Las Denominaciones de Origen de Castilla y León con mayor volumen de comercialización no se libraron de esta disminución de las ventas en mercados extranjeros. Es por tanto, fundamental desarrollar buenos canales de comercialización y comunicación para favores la venta y la mejora de la imagen corporativa. En este sentido, Internet y la era digital tiene mucho que decir (Burgos y León, 2001: 89).

Rafael del Rey, sostiene que las denominaciones de origen (D.O) e indicaciones geográficas protegidas son un elemento extraordinario para potenciar el consumo de vino, los vinos de calidad y promocionarlos.

Un total de 1,3 millones de botellas fueron comercializadas en 2011 fuera de España, de las que más de un millón fueron de tintos de reserva, lo que permitió mantener la cifra total de ventas ligeramente por encima de 3,83 millones de botellas, muy parecida a la de 2010, compensando así el fuerte descenso en el mercado nacional (Diputación Provincia de Valladolid, 2011).

La calidad de los vinos de esta tierra es fruto del buen hacer de las personas que trabajan en ello, cuidando con esmero todo lo que tiene que ver con el vino. El enoturismo o turismo enológico tiene como objetivo potenciar y gestionar la riqueza vitivinícola de una determinada zona, en este caso la provincia de Valladolid, por todo ello, la Institución Provincial, en el año 1999, decidió apostar fuerte por la creación del Museo Provincial del Vino en el castillo de Peñafiel.

Este museo cumple también el objetivo de promocionar el conocimiento a través del mundo del vino, de la provincia de Valladolid, de sus aspectos culturales y geográficos. Este museo cuenta con una importante variedad de actividades que se adaptan a los diferentes intereses del público: catas dirigidas, cursos de catas para profesionales o para los que empiezan que quieran iniciarse durante un fin de semana. Incluso se ofertan divertidos talleres para los escolares como "El juego de los sentidos". La filosofía de este proyecto, contempla el diálogo con otras regiones vitivinícolas del mundo: Vinus Mundi es un programa abierto que nos permite asomarnos a ellas a través de exposiciones, catas dirigidas, conciertos etc.... (Guía del Vino Anaya, 2007). 
Valladolid es una ciudad, que con el paso del tiempo se ha convertido en una de las ciudades de referencia del vino a nivel nacional en esta área. El pasado 2011, acogió una de las ferias más importantes del vino de nivel mundial: Iberwine.

Esta feria del vino español, portugués y latinoamericano tuvo lugar del 25 al 27 de mayo en el recinto ferial de la ciudad. Fue un evento sólo para profesionales de la industria del vino. Con este encuentro se pretende también promover los negocios para desarrollar una nueva conciencia de la industria del vino para su posterior desarrollo en todos los frentes: económico, social y medio-ambiental. Además, Iberwine 2011 quiere ir aún más allá, y por eso, en su nueva concepción fusiona el vino, los negocios, la cultura y el arte para crear un novedoso evento de sensaciones dentro y fuera del recinto ferial con áreas comerciales, áreas Vips, área de descanso...

En Febrero de 2011 tuvo lugar el Concurso Vino de Museo 2011, convocado por el presidente de la Diputación de Valladolid. En dicho concurso podrán participar todas las bodegas de la Comunidad de Castilla y León siempre que estén adscritas a una de las Denominaciones de Origen de la región o bajo la figura de Calidad de Vino de la Tierra de Castilla y León. Tuvo lugar en la sede del Museo Provincial del Vino en el Castillo de Peñafiel. El director técnico de cata fue el presidente de los sumilleres de Castilla y León, Pablo Martín afirmando que la labor de un sumiller es ayudar al consumidor a elegir el vino adecuado con el plato y contribuir a descubrir el amplio mundo de sabores y olores con que puede disfrutarse de una copa de vino (Norte de Castilla electrónico, 2011).

Por otro lado, como elemento estratégico de comunicación y de difusión de la cultura del vino surge en 2004 la oficina de Enoturismo de Valladolid, implantada para promocionar y comercializar los vinos de la provincia, en colaboración con las principales empresas del sector, bodegas, alojamientos y municipios, pretende organizar, coordinar y aunar los esfuerzos de un sector en auge, ofreciendo al visitante nuevas formas de entender y comprender la tradición y la oferta relacionada con el mundo del vino. La oficina de enoturismo ofrece diferentes alternativas para visitar las bodegas de Valladolid:

-Rutas de un día o de fin de semana por cada una de las denominaciones de origen que nos recorren.

-Ruta circular para visitar de forma completa las cuatro zonas vinícolas y un programa semanal para los más apasionados por los vinos de alta expresión. En definitiva, un turismo de calidad, ofreciendo visitas guiadas garantizadas, visitas en idiomas, catas dirigidas y venta de productos de cada zona.

-Rutas que combinan todos los tipos de recursos existentes en cada una de las zonas. Rutas por cada una de las Denominaciones de origen que recorren la provincia, Ribera del Duero, Rueda, Cigales, Toro y Tierras de León.

-Ruta Urbana enogastronómica en la que se adentra en el Valladolid histórico, combinando lo mejor del Patrimonio cultural de la ciudad con las zonas de vinos y pinchos, todo ello relacionado con el esplendoroso pasado vitivinícola que vivió la ciudad en la época de Felipe II. 
De entre las 256 bodegas elaboradoras de caldos en la Ribera, más de un centenar son teóricamente visitables, casi todas con cita previa, lo que representa el $48 \%$ del total. Además, es la única Denominación de Origen que cuenta con hoteles y restaurantes en las instalaciones de varias bodegas y, por tanto, es la comarca que más ha apostado por desarrollar el turismo del vino en Castilla y León, aunque de momento con escasa coordinación. Cinco bodegas cuentan con establecimientos de hostelería en el entorno de sus instalaciones: Arzuaga-Navarro, Emina ${ }^{6}$ y Matarromera en la provincia de Valladolid, Torremilanos y Prado Rey en Burgos. Algunas más cuentan con restaurantes vinculados a las bodegas como Bodegas Hnos. Pérez Pascuas, Emilio Moro, Pesquera, Viña Mayor, Bodegas Durón.

Fundamentalmente como factor importante a destacar hay que hablar de la creación de las nuevas bodegas pertenecientes a grandes grupos empresariales vinícolas tan importantes como Codorniú, Domecq, Solís y Torres que viendo el potencial de la región, ya sea por las grandes posibilidades que ofrece en cuanto a la calidad del producto, infraestructuras, servicios y cercanía de la capital española, han invertido grandes cantidades de dinero para posicionarse como referentes del enoturismo en la Ribera del Duero.

El papel del vino ha venido evolucionando con el tiempo, cambiando desde una importante fuente nutritiva que era hasta convertirse en complemento cultural de la comida y de la convivialidad, compatible con un estilo de vida sano. El arte de la viticultura ha evolucionado, pero un principio que no ha cambiado para nada es la tradición Europea de presentar el vino y de comunicar sobre él mismo, centrándose en los orígenes, la herencia y la vinicultura.

Se suele asociar el vino con la gastronomía, la historia, la calidad de los productos locales y cierta solemnidad social. Como tal, a pesar de las diferencias en las pautas de consumo que se observan a través de toda la UE, el consumo moderado sigue siendo la norma general y es sólo una pequeña minoría la que hace un uso indebido del vino. Que el mundo del vino está cambiando es una realidad tangible hasta hace poco, el consumo general de vino estaba creciendo gracias a los mercados emergentes, sin embargo, la recesión ha deprimido el consumo total. El panorama vitivinícola español está siendo testigo de la llegada de grandes inversiones al sector en forma de infraestructura y tecnología con la construcción de numerosas bodegas (Del Rey, 2010:23).

Actualmente, existe todo un mundo alrededor del vino, nuevas tendencias relacionadas con este sector, y la aparición de nuevos consumidores con gustos

\footnotetext{
${ }^{6}$ Emina es el Nuevo Centro de Interpretación Vitivinícola de la Ribera del Duero, fue inaugurado en la primavera del año 2006. Es el nuevo proyecto enoturístico del Grupo Matarromera situado en San Bernardo de Duero (Valladolid). A finales del año 2007 se finalizó la construcción de Emina D.O. Rueda, en la población de Medina del Campo. Ambas bodegas están orientadas fundamentalmente hacia el enoturismo. Consultar página Web: www.emina.es
} 
diferentes entre ellos, se habla de una cultura que caracteriza a los diferentes países en la que los vinos españoles se han abierto un hueco en los mercados internacionales, siendo muy valorada la relación calidad-precio. Los jóvenes que consumen vino en distintos países tienen bastantes más cosas en común que las generaciones que les precedieron, especialmente en los mercados occidentales. La llamada Generación Y o la Generación del "milenio" es menos individualista; a sus miembros les gusta sentir que forman parte de un grupo.

En esta nueva realidad de ocio y consumo de actividades relacionadas con la cultura del vino, se abre un abanico de ofertas en las diferentes denominaciones de Origen y Rutas de Vino por toda la geografía de la Ribera del Duero. El enoturista busca un encuentro experiencial no sólo y únicamente con el consumo tangible del vino como producto/sustancia/bebida sino que quiere encontrar vivencias reales con todo lo relacionado con este producto de gran tradición. Así, un turista del vino catará el producto, visitará su lugar de elaboración, querrá conocer a sus creadores, comerá en la bodega y quizá pase también la noche; disfrutando del paisaje y de la riqueza cultural y monumental de la comarca.

En esta investigación se ha llevado a cabo para la recogida de información técnicas cuantitativas como es la puesta en marcha de un cuestionario-descriptivo y autoadministrado con preguntas abiertas y cerradas. Además de la utilización de esta fuente primaria se han empleado fuentes secundarias para la consulta de datos e información en revistas y páginas web. De esta forma, se podrá llegar a los objetivos marcados.

\section{METODOLOGíA}

Entre los principales objetivos de la investigación se destacan los siguientes:

-Conocer el perfil del enoturista que visita la D.O. Ribera del Duero.

-Conocer las tendencias y hábitos de consumo de estos turistas del vino.

-Averiguar cuánto dinero están dispuestos a pagar por los servicios que ofrecen las bodegas de esta zona.

Para ello, se ha diseñado y distribuido un cuestionario en el año 2012 con el fin de conocer el perfil del turista del vino en la D.O. Ribera del Duero. Se elaboró un cuestionario bastante completo (más de 20 preguntas) y se realizó previamente como proyecto piloto a 10 visitantes en una bodega de la D.O. Ribera del Duero ${ }^{7}$. La finalidad era perfeccionarlo y detectar con suficiente antelación, posibles errores para su posterior difusión.

El cuestionario incluye 30 preguntas distribuidas en tres partes (cada una de estas partes se centra en una ámbito del tema). La mayoría de ellas son cerradas y

${ }^{7}$ Cuestionarios realizados como ya se ha citado antes en Bodegas Hnos. Pérez Pascuas, S.L. (D.O. Ribera del Duero, Pedrosa de Duero - Burgos). 
dicotómicas (respuesta de elección y excluyentes una de la otra, son de tipo SI o NO), también existe un alto porcentaje de preguntas abiertas y de respuesta múltiple (en las que el encuestado puede escoger varias opciones) y otras, con diversas escalas ${ }^{8}$ (tipo escala Likert o Guttman) en las que debe valorar numéricamente (según su opinión) las posibles respuestas planteadas.

En general, la encuesta funcionó bien y no fue necesario introducir modificaciones importantes. Sólo se modificó el orden de algunas de las preguntas para que fueran más claras y enfocar mejor el tema de estudio al encuestado. Se detectó que al ser un cuestionario bastante extenso, el público encuestado tardaba bastante tiempo en responder todas las preguntas. Era vital la presencia del encuestador para orientar las preguntas del cuestionario al encuestado. El tiempo ${ }^{9}$ medio de duración del cuestionario fue de 15 minutos por persona. Esto sirve como experiencia para elaborar sucesivos cambios en los cuestionarios.

\subsection{Estructura del Cuestionario.}

En la primera parte, se incluyen preguntas relacionadas con la valoración general de una visita a una bodega, de esta forma se capta de forma rápida si el visitante ya ha tenido una primera experiencia en visitar bodegas en la D.O. Ribera del Duero. De esta forma, se puede detectar la motivación del enoturista en su visita.

En el paradigma turístico, el concepto de la motivación está clasificado por dos fuerzas: las internas y las externas (Dann, 1981). Las fuerzas internas son aquellas que responden a aspectos intrínsecos (de deseo), como el deseo de escapar de la rutina, buscar auténticas experiencias y relacionarse. Por otro lado, las fuerzas externas son aquellas que vienen afectadas por el medio externo, es decir, por el atractivo de la zona y la zona natural (Crompton, 1979).

Las primeras dos preguntas del cuestionario cuestionario, hacen referencia a la comarca o Denominación de Origen donde se ha visitado alguna vez una bodega. De esta forma, se puede tener un primer contacto sobre si el visitante tiene más o menos experiencias en la práctica del enoturismo.

Las preguntas $\mathrm{N}^{\circ} 3$ y $\mathrm{N}^{\circ} 4$, son preguntas que sirven para conocer si el encuestado ha participado o ha accedido a pagar en alguna ocasión en las entradas a bodegas de la zona y si se ha mostrado reacio ante dicha situación.

En las siguientes preguntas $\mathrm{N}^{\circ} 5, \mathrm{~N}^{\circ} 6$ y $\mathrm{N}^{\circ} 7$, tienen como objetivo evaluar la experiencia en el servicio de la visita en bodega y miden si el encuestado encuentra interesante el pagar una tarifa de entrada por ver una bodega. Se plantean diferentes alternativas sobre si el turista se muestra muy distante a pagar una cantidad u otra de

\footnotetext{
8Se explicarán en los siguientes capítulos en nota al pie de página.

${ }^{9}$ La duración del cuestionario, depende de la capacidad de comprensión de cada persona y de su edad.
} 
dinero por determinados servicios en una bodega. La pregunta No8, plantea una pregunta abierta para que el encuestado ofrezca y explique las razones a la contestación de la pregunta Nº7.

En la última pregunta del primer bloque, se realiza una pregunta totalmente abierta $\left(\mathrm{N}^{\circ}\right.$ ), de esta forma, la persona que responde puede elegir libremente un servicio que echa en falta en las visitas a las bodegas.

Esta pregunta resulta clave para perseguir otro de los objetivos de esta investigación que es conocer y saber qué valora más el visitante de los servicios de una bodega y saber qué le gustaría que éstas ofrecieran (en caso de carecer de dicho servicio) para poder ofrecer más calidad y satisfacción al cliente en un futuro.

En la segunda parte, se estudia el interés del encuestado y se aplica el método de valoración contingente.

Las dos primeras preguntas, valoran el interés y los criterios de elección a la hora de visitar una bodega; por ejemplo en la pregunta $\mathrm{N}^{\mathrm{o}} 2$, al ser una pregunta de respuesta múltiple, el encuestado puede escoger varias opciones o todas. La tercera, cuarta y quinta cuestión, estudian la frecuencia y la época estacional en la que se realizan las visitas. De este modo, podrá deducirse en qué momento se realizan más desplazamientos.

En las siguientes preguntas $\mathrm{N}^{\circ} 6, \mathrm{~N}^{0} 7, \mathrm{~N}^{0} 8$ y $\mathrm{N}^{\circ}$, se pretende tener un control y conocimiento para saber si la persona que visita bodegas, pasa la noche fuera del hogar o el recorrido y tiempo que dedica a los desplazamientos a las zonas de enoturismo. Así, se podrá saber si el enoturista realiza un determinado gasto (bajo/medio/alto) para desplazarse a ver la bodega o si por el contrario, escoge el regreso al domicilio particular.

En las preguntas $\mathrm{N}^{0} 10, \mathrm{~N}^{\mathrm{a}} 11$ y No12, se aplica el método Coste de Valoración Contingente. De esta forma, se establecen unos parámetros mínimos y máximos para saber cuánto dinero el visitante estaría dispuesto a pagar por visitar una bodega o comer en las instalaciones de la misma.

Las últimas preguntas $\mathrm{N}^{0} 13$ y $\mathrm{N}^{\mathrm{a}} 14$ de la segunda parte, se caracterizan por ser preguntas abiertas y de recuerdo. La cuestión $\mathrm{N}^{0} 14$, sugiere un control sobre las contestaciones de las preguntas de la primera parte y sobre el estudio de análisis del buen funcionamiento de los servicios que pueda ofrecer una bodega.

El cuestionario termina con una tercera parte de 7 cuestiones de carácter sociodemográfico sobre la persona encuestada:

La pregunta $\mathrm{N}^{0} 15$, pretende conocer el año de nacimiento del encuestado. Este tipo de pregunta forma parte de las cuestiones que intentan caracterizar al estereotipo de enoturista. De esta forma, junto con las variables de renta, sexo y estudios 
principalmente, se podrá establecer un perfil adecuado del enoturista y así, dirigir las acciones de gestión, comunicación y marketing de un modo eficaz hacia determinados públicos.

Con la pregunta de variable sexo, se quiere detectar si existen diferencias significativas entre los comportamientos y preferencias de los servicios de enoturismo entre hombres y mujeres.

La pregunta $\mathrm{N}^{0} 17$ a través del conocimiento del nivel de estudios cursados, se obtiene más información sobre el perfil del visitante en cuanto a su formación.

Con la pregunta $\mathrm{N}^{\circ} 18$, nivel de renta mensual por unidad familiar, se conoce cuál es el status socioeconómico del turista. No se preguntaba la renta directamente, sino que se establecieron varios tramos con el fin de no llegar a una situación incómoda y embarazosa para el encuestado.

La cuestión sobre el número de miembros de la unidad familiar, es necesaria para poder ajustar el status económico del visitante, una vez sabido el valor de la renta familiar.

La pregunta No20, ¿Pertenece a algún Club de Vino?, permite conocer el vínculo del encuestado y grado de pertenencia al sector vitivinícola. Esta cuestión es importante ya que se podrá saber qué grado de relación tiene el turista con el sector del vino, es decir, detectar los encuestados con mayor conocimiento del vino y saber sus particularidades. En este aspecto, si el visitante perteneciera a un Club de Vinos o Asociación, su grado de relación respecto al vino sería más alto que aquel que no perteneciera a ninguno.

La última pregunta $\mathrm{N}^{\mathrm{o}} 21$, pretende, por un lado, conocer la procedencia del visitante y por otro, tener constancia del lugar de residencia, que no tiene por qué coincidir necesariamente con el de procedencia. Así, se conocerá el porcentaje de visitantes a la Denominación de Origen Ribera del Duero que vienen de una comunidad u otra, e incluso fuera de España.

\subsection{Método utilizado en el Cuestionario: Método Coste de Valoración Contingente.}

El método utilizado en varias de las preguntas (se verá a continuación) del primer cuestionario elaborado, es el Método Coste de Valoración Contingente. Se trata de uno de los métodos directos de valoración económica que tiene como objetivo valorar diferentes tipos de medios y bienes que comenzó a proponerse hace medio siglo.

A través de este método, las encuestas permiten representar un mercado hipotético, donde la oferta viene representada por la persona entrevistadora y la demanda por la entrevistada, existiendo numerosas variantes en la formulación de las preguntas para obtener un precio del bien sin mercado real. 
Durante los últimos años, el método de Valoración Contingente ha predominado en Europa en la valoración de externalidades ambientales frente a otros métodos (Barreiro Hurlé y Pérez, 1997).

El $\mathrm{MVC}^{10}$ se ha ido implantando como medio para valorar económicamente bienes públicos (tanto de carácter ambiental como de otros tipos) tanto por medios académicos y técnicos (mayor versatilidad y flexibilidad, capacidad de cuantificar valores de no uso, etcétera) como institucionales. Ello se demuestra por el hecho de que hasta la fecha existen no menos de 1500 aplicaciones del MVC en todo el mundo (Carson et al., 1995).

La idea de utilizar encuestas directas a individuos para obtener el valor que otorgan a un bien es debida a Ciriacy-Wantrup, economista y profesor de Economía de los Recursos Naturales en la Universidad de Berkely en California. En su libro Resource Conversation: Economics and Policie, Ciriacy-Wantrup (1952), recomendaba el uso del método de la entrevista directa para medir los valores asociados a los recursos naturales.

En la investigación, se aplica el método de valoración contingente estableciendo unos parámetros de mínimos y máximos en la posible tarifa de entrada a bodegas de la D.O. Ribera del Duero, al igual que una posible degustación y almuerzo en la misma. A partir de la relación de los datos sociodemográficos y las diversas cuestiones de los tres bloques del cuestionario, se obtienen resultados que ayudan a conseguir los objetivos planteados.

Los valores económicos escogidos han sido obtenidos previamente al testar el cuestionario en Bodegas Hnos. Pérez Pascuas, S.L. en diciembre de 2011 (Pedrosa de Duero - D.O. Ribera del Duero - Burgos).

Finalmente, se han utilizado cantidades intermedias para valorar cada una de las cuestiones; como es el caso de la pregunta $\mathrm{N}^{\circ} 6$, en la que se intenta conocer si el visitante estaba dispuesto a pagar $6 €$ por visitar una bodega y tomar una pequeña degustación de vino. En la pregunta No7 sucede los mismo; se quiere saber si el interesado pagaría $3.00 €$ por sólo visitar la bodega (sin degustación). Finalmente, en la cuestión $\mathrm{N}^{\mathrm{o} 9}$, se pretende averiguar el dinero que el enoturista estaba dispuesto a pagar por el servicio completo, es decir, visitar la bodega, degustar un vino y comer en las instalaciones de la misma con vino incluido (esta pregunta se incluye en la segunda parte del cuestionario).

En esta última pregunta (pregunta $\mathrm{N}^{\circ}$ ) ) existen varias opciones para elegir una única respuesta. Se escogieron diferentes tarifas de precios para el servicio completo y menú en bodega; estableciendo un precio mínimo de $30.00 €$ y máximo de $60.00 €$.

${ }^{10}$ Siglas del Método Coste de Valoración Contingente. 


\subsection{La Muestra.}

La muestra se ha enfocado de forma seleccionada y restringida en diferentes puntos de información turística de la zona de la D.O. Ribera del Duero. Dentro de la geografía de la comarca, se han escogido estos puntos estratégicos para obtener información por parte de los turistas que se desplazaban de su lugar de origen para visitar en su mayoría las bodegas de la Denominación de Origen Ribera del Duero. Es por ello, que se ha seguido el criterio del investigador para llevar a cabo una selección de la muestra por cuotas. Este último estudio es muy utilizado en estudios de mercado y la responsabilidad del encuestador es alta ya que es quien tiene la decisión en cada momento para la selección de la muestra (Ghiglione y Matalon, 1989). Un total de 240 cuestionarios se distribuyeron durante el año 2012.

\subsection{Distribución del Cuestionario.}

El reparto y distribución del cuestionario tuvo una duración de cinco meses en total (desde enero de 2012 hasta mayo del mismo año).

Durante los primeros meses, se observa claramente un importante descenso de los turistas y visitantes a bodega, ya que fue posterior a la Navidad de 2011. Se escogió precisamente este período para realizar los cuestionarios a profesionales del sector y aprovechar la época primaveral (mes de marzo) que es cuando comienza el turismo enológico en esta región. En total, se repartieron 240 cuestionarios en los siguientes municipios de las provincias ${ }^{11}$ de Valladolid y Burgos:

- Aranda de Duero - Burgos: Oficina de Turismo de Aranda de Duero (50 cuestionarios).

- Pedrosa de Duero - Burgos: Encuestas aleatorias en Bodegas Hermanos Pérez Pascuas, S.L. (20).

- Sotillo de la Ribera - Burgos: Palacio de los Serrano (Posada Rural) (20).

- Roa de Duero - Burgos: Oficina de Turismo de Roa (30).

- Peñafiel - Valladolid: Oficina de Turismo de Peñafiel (40).

- Peñafiel- Valladolid: Museo del Vino (40).

- Quintanilla de Onésimo - Valladolid: Hotel Fuente de La Aceña (20).

- Peñafiel - Valladolid: Hotel Ribera del Duero (20).

El cronograma que se siguió en la distribución y recogida de los cuestionarios, es el que se explica a continuación:

\footnotetext{
${ }^{11}$ Se han escogido principalmente estas provincias porque son las que tienen un mayor número de hectáreas de viñedo en la D.O. Ribera del Duero (Burgos, Valladolid, Soria y Segovia). Además son las regiones que más turistas del vino reciben porque es donde están las bodegas más conocidas e importantes de la Denominación de Origen Ribera del Duero. Por tanto tuvo una distribución rural preferentemente.
} 
1. Primero, se estableció contacto con el responsable de cada Organismo (Entidad, Empresa o Institución a la que iban dirigidos los cuestionarios) por correo electrónico en diciembre de 2011.

2. Una vez enviado el correo electrónico en diciembre de 2011 como primer punto de contacto, se llamó telefónicamente para hablar directamente con la persona responsable y se explicó brevemente el motivo de la investigación (mediados de diciembre) y de la realización de los cuestionarios.

3. Cuando se obtuvo el visto bueno por parte de los responsables de las empresas, se estableció y fijó una fecha para entregarles de forma física y personal los cuestionarios.

4. Entre el 8 y el 11 de enero de 2012, se efectuó el desplazamiento para entregar los cuestionarios ${ }^{12}$ de forma física y así, poder establecer un contacto personal con la persona que iba a distribuir los cuestionarios en la Oficina de Turismo, el Hotel, Museo o Bodega. Después se especificó el momento de recogida de los mismos.

5. Entre el 2 y el 6 de junio de 2012 se recogieron todos los cuestionarios (176 en total de los 240 distribuidos) y se preguntó por posibles incidencias surgidas.

6. Finalmente, se agradeció la colaboración por escrito y se comenzó el análisis con los datos estadísticos obtenidos a partir de los cuestionarios.

Los cuestionarios se efectuaron a lo largo de toda la semana, principalmente en fines de semana y días festivos que es el momento en el que se realizan más desplazamientos y se reciben más turistas en la zona.

Todas las encuestas fueron repartidas a lo largo de los meses de enero, febrero, marzo, abril y principios de mayo de 2012. Se recogieron todas ellas a principios de junio de 2012. Se trataron estadisticamente 176 cuestionarios de los 240 repartidos en un principio. Para obtener datos cuantitativos a través de las preguntas cerradas del cuestionario, se utilizaron medidas estadísticas como la suma y los promedios, para obtener porcentajes definitorios y claros sobre las cuestiones planteadas. De este modo, se conocería qué comportamientos, actitudes y datos se repiten más, así como conocer cuáles son las costumbres y preferencias más apreciadas por los encuestados. Para analizar y tratar los datos se empleó el programa Microsoft Office Excel. Los resultados se expondrán en el siguiente capítulo con la ayuda de varios gráficos elaborados gracias al programa Microsoft Office Excel.

Los datos cualitativos de tendencias de los turistas del vino se analizaron gracias a la inclusión de preguntas abiertas.

\section{ANÁLISIS Y DISCUSIÓN}

En la primera parte del cuestionario ${ }^{13}$ que versa sobre los servicios de enoturismo en Bodegas de la D.O. Ribera del Duero (2012), se destacan las siguientes preguntas más importantes:

${ }^{12}$ El cuestionario piloto se puso en marcha en noviembre de 2011 en Bodegas Hnos.Pérez Pascuas, S.L. 
En la pregunta $\mathrm{N}^{0} 1$, sobre si se había visitado alguna vez una bodega, todas las respuestas obtenidas fueron afirmativas; ya que dichos cuestionarios fueron distribuidos en lugares estratégicos, donde evidentemente existe un mayor porcentaje de turistas del vino; por lo tanto, estos cuestionarios se han dirigido hacia un público objetivo concreto, personas que visitan bodegas o que en alguna ocasión se han acercado a alguna de ellas. En este caso, se plantea la cuestión para la visita de una bodega en cualquier Denominación de Origen de España o región, tanto a nivel nacional como internacional.

La pregunta $\mathrm{N}^{\mathrm{2}} 2$, alude a la comarca o región donde se han realizado las visitas a las bodegas. La mayoría de los encuestados visitaron más bodegas situadas en la D.O. Ribera del Duero. Casi un 47\% visitaron sólo la Ribera del Duero, mientras que el 8\% visitaron Ribera y otras Denominaciones (de este $8 \%$, un 4,5\% visitaron Ribera y otras Denominaciones de Origen de Castilla y León), casi un 8\% visitaron sólo La Rioja, un 5\% visitaron Ribera y Rioja, y un 15\% visitaron otras Denominaciones de Origen que no eran ni Rioja, Ribera y otras Denominaciones de Origen de Castilla y León.

Como puede observarse, tanto la D.O. Ribera del Duero como la D.O.C. Rioja son las zonas vitivinícolas más visitadas. Es lógico que la D.O. Ribera del Duero se encuentre por delante de Rioja, ya que los cuestionarios fueron efectuados en lugares y zonas receptivas de turismo enológico de la D.O. Ribera del Duero.

Tabla 1. Visitas a Denominaciones de Origen I

\begin{tabular}{|l|r|r|r|}
\hline Respuesta & Tamaño de la & Número de \\
sucesos & $\begin{array}{c}\text { Proporción } \\
\text { de la } \\
\text { muestra }\end{array}$ \\
\hline Ribera solo & 176 & 84 & $\mathbf{0 , 4 7 7}$ \\
\hline Ribera + Rioja & 176 & 10 & $\mathbf{0 , 0 5 7}$ \\
\hline Ribera +otros & 176 & 15 & $\mathbf{0 , 0 8 5}$ \\
\hline Ribera + CyL & 176 & 8 & $\mathbf{0 , 0 4 5}$ \\
\hline Otras D.O. CyL & 176 & 19 & $\mathbf{0 , 1 0 8}$ \\
\hline Rioja solo & 176 & 14 & $\mathbf{0 , 0 8 0}$ \\
\hline Rioja +otros & 176 & 0 & $\mathbf{0 , 0 0 0}$ \\
\hline Otros & 176 & 26 & $\mathbf{0 , 1 5}$ \\
\hline
\end{tabular}

Fuente: elaboración propia a partir de los datos obtenidos

Si se observan bien los datos, se aprecia que la D.O. Ribera del Duero junto con Rioja y resto de las Denominaciones enclavadas en Castilla y León, son las más visitadas. Se aprecia que el porcentaje de personas que sólo visitaron Rioja es muy alto con un 9\%. 
También es apreciable el porcentaje de personas que visitaron Ribera y resto de Denominaciones situadas en Castilla y León. La mayoría de estas Denominaciones de Castilla y León se encuentran situadas en la provincia de Valladolid. La razón de estos resultados se debe a que los lugares y centros de turismo escogidos para realizar los cuestionarios, han sido focos estratégicos situados en Castilla y León y, además todos ellos situados en lugares de la provincia de Valladolid. Como puede verse el mayor porcentaje lo alcanzan las visitas sólo realizadas a la D.O. Ribera del Duero.

En la tercera pregunta se preguntaba sobre si en alguna ocasión los turistas tuvieron que pagar tarifa por visitar una bodega. Un 71\% de los encuestados no han pagado ningún tipo de tarifa. El resto de los visitantes, un $29 \%$, de alguna manera ya sea por pago individual o pago efectuado a través de un grupo organizado (al realizar una visita con un tour y agencia), sí tuvieron que pagar por la visita.

A partir de las siguientes preguntas se muestran varios resultados a partir del diagrama de cajas o "Box Plot".

El diagrama de cajas o boxplot es un gráfico representativo de las distribuciones de un conjunto de datos en cuya construcción se usan cinco medidas descriptivas: mediana, primer cuartil, tercer cuartil, valor máximo y valor mínimo.

Esta presentación visual, asocia las cinco medidas que suelen trabajarse de forma individual. Presenta al mismo tiempo, información sobre la tendencia central, dispersión y simetría de los datos de estudio. Además, permite identificar con claridad y de forma individual, observaciones que se alejan de manera poco usual del resto de los datos. A estas observaciones se les conoce como valores atípicos.

El nombre original del gráfico introducido por Jhon Tukey en 1977 es Box and whisker plot, es decir, diagrama de caja y bigote. En efecto, el gráfico consiste en un rectángulo (caja) de cuyos lados superiores e inferior se derivan respectivamente, dos segmentos: uno hacia arriba y uno hacia abajo (bigotes).

Las partes del boxplot se identifican como sigue:

- Límite superior: es el extremo superior del bigote. Las opiniones por encima de este límite se consideran atípicas.

- Limite inferior: es el extremo inferior del bigote. Las opiniones por debajo de este valor se consideran atípicas.

- Mediana: coincide con el segundo cuartil. Divide a la distribución en dos partes iguales. De este modo, $50 \%$ de las observaciones están por debajo de la mediana y $50 \%$ está por encima.

- Primer cuartil (Q1): por debajo de este valor se encuentra como máximo el 25\% de las opiniones de los encuestados.

- Tercer cuartil (Q3): por debajo de este valor se centran como máximo el 75\% de las opiniones de los encuestados. 
- Valores atípicos: son opiniones que están apartadas del cuerpo principal de datos. Pueden representar efectos de causas extrañas, opiniones extremas o en el caso de la tabulación normal, errores de medición o registro.

- Media aritmética: es lo que tradicionalmente se conoce como promedio. Originalmente no forma parte del boxplot, sin embargo, se consideró su inclusión para dar una idea del puntaje general obtenido por pregunta.

La línea que representa la mediana indica la simetría. Si está relativamente en el centro de la caja de distribución es simétrica. En este aspecto, la media, la moda y la mediana coinciden y los datos se distribuyen de igual forma a ambos lados de estas medidas. En el contexto, hay igual número de opiniones por encima que por debajo de la mediana.

Si por el contrario se acerca al primer cuartil, la distribución pudiera ser sesgada a la derecha (asimétrica positiva). En este caso, la media es mayor que la mediana y los datos tienden a concentrarse hacia la parte inferior de la distribución y se extiende más a la derecha.

Si se acerca al tercer cuartil la simetría es sesgada a la izquierda (asimétrica negativa). Por tanto, los datos tienden a concentrarse hacia la parte superior de la distribución y se extiende más hacia la izquierda. La media en este ejemplo es menor que la mediana. Los valores mínimos y máximos aportan el dato más pequeño o más grande de la distribución, respectivamente.

Tabla 2. Cobro de Visitas a bodegas de la D.O. Ribera del Duero

\begin{tabular}{|c|c|c|c|c|c|c|c|c|}
\hline $\begin{array}{l}\text { Respuest } \\
\text { a }\end{array}$ & $\begin{array}{c}\text { Tamaño } \\
\text { de la } \\
\text { muestra }\end{array}$ & $\begin{array}{c}\text { Número } \\
\text { de } \\
\text { sucesos }\end{array}$ & $\begin{array}{l}\text { Proporció } \\
\text { n de la } \\
\text { muestra }\end{array}$ & $\begin{array}{c}\text { Estimació } \\
\text { n de } \\
\text { Wilson } \\
\text { para la } \\
\text { proporció } \\
\text { n de la } \\
\text { muestra }\end{array}$ & $\begin{array}{c}\text { Error } \\
\text { Standard } \\
\text { de la } \\
\text { Estimació } \\
\mathbf{n}\end{array}$ & $\begin{array}{l}\text { Marg } \\
\text { en de } \\
\text { Error }\end{array}$ & $\begin{array}{c}\text { Límite } \\
\text { Inferior } \\
\text { para el } \\
\text { Interval } \\
\text { o de } \\
\text { Confian } \\
\text { za al } \\
95 \%\end{array}$ & $\begin{array}{c}\text { Límit } \\
\text { e } \\
\text { Super } \\
\text { ior } \\
\text { para } \\
\text { el } \\
\text { Interv } \\
\text { alo de } \\
\text { Confi } \\
\text { anza } \\
\text { al } \\
95 \%\end{array}$ \\
\hline$S i$ & 176 & 51 & 0,290 & 0,294 & 0,034 & 0,067 & 0,228 & 0,361 \\
\hline No & 176 & 125 & 0,710 & 0,706 & 0,034 & 0,067 & 0,639 & 0,772 \\
\hline
\end{tabular}

Fuente: elaboración propia a partir de los datos obtenidos 
El intervalo de los que sí pagaron (pregunta $\mathrm{N}^{\circ} 4$ ) oscila entre un mínimo de $2 €$ (este sería el valor mínimo) hasta un máximo de $12 €$ (dato máximo de la distribución). En la siguiente tabla 3 y figuras pueden observarse los datos sobre la mediana alcanzada, los índices máximos y mínimos de tarifa que el público está dispuesto a pagar.

Tabla 3. Media obtenida de Tarifa para la visita de una bodega

\begin{tabular}{|c|c|c|c|c|}
\cline { 3 - 5 } \multicolumn{2}{c|}{} & \multicolumn{3}{c|}{ Precio en $€$} \\
\hline $\begin{array}{c}\text { Número de } \\
\text { Encuestas } \\
\text { Realizadas }\end{array}$ & $\begin{array}{c}\text { Número de } \\
\text { Encuestas } \\
\text { Respondidas }\end{array}$ & $\begin{array}{c}\text { Limite Inferior } \\
\text { Intervalo de } \\
\text { Confianza para la } \\
\text { Media al 95\% }\end{array}$ & Media & $\begin{array}{c}\text { Limite Superior } \\
\text { Intervalo de } \\
\text { Confianza para la } \\
\text { Media al 95\% }\end{array}$ \\
\hline 176 & 30 & 4,06 & 4,93 & 5,80 \\
\hline
\end{tabular}

Fuente: elaboración propia a partir de los datos obtenidos

Figura 1. Precio de entrada.

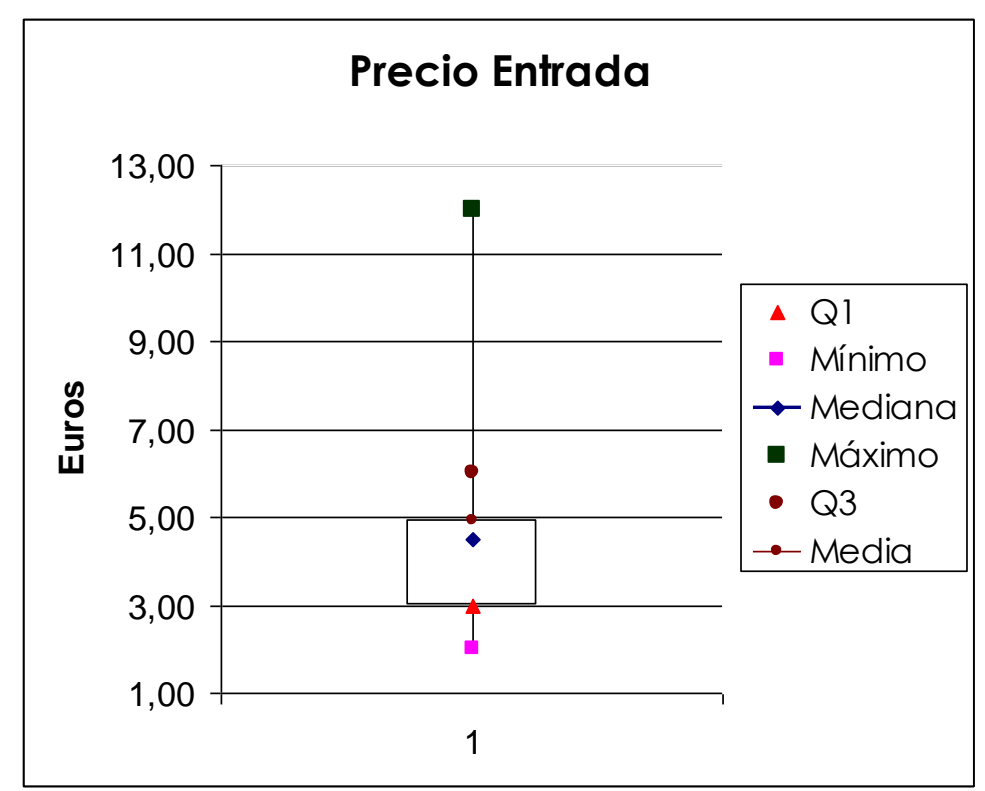

Fuente: elaboración propia a partir de los datos obtenidos

El diagrama de cajas muestra que la media obtenida para el pago de una tarifa es de un valor de 4,93 €. Una cantidad que está por encima del cuartil Q1 (que es 3) y por debajo del cuartil Q3 (tiene un valor de 6). La mediana tiene un valor de 4,50; por lo tanto es menor que la media. Es una distribución simétrica positiva. Los datos tienden a concentrase hacia la parte inferior de la distribución y se extienden más hacia la derecha.

La pregunta $\mathrm{N}^{\mathrm{o}}$, cuestiona la duración de la visita. El tiempo medio de duración de una visita a las instalaciones de la bodega es de 54 minutos por enseñar la bodega y 
ofrecer, en la mayoría de los casos, una pequeña degustación. Existen personas que han realizado una visita profesional y de mayor duración, con una estimación de tiempo de dos horas (punto máximo alcanzado). Son visitas que incluyen catas y una explicación más completa. En cambio, hay recorridos que tan sólo duran 15 minutos y sin degustación (punto mínimo).

Normalmente, el público queda más satisfecho cuando las visitas duran aproximadamente 60 minutos como máximo y se ofrece una pequeña degustación.

Tabla 4. Duración de la Visita I

\begin{tabular}{|c|c|c|c|c|}
\cline { 3 - 5 } \multicolumn{2}{c|}{} & \multicolumn{3}{c|}{$\begin{array}{c}\text { Tiempo en } \\
\text { minutos }\end{array}$} \\
\hline $\begin{array}{c}\text { Número de } \\
\text { Encuestas } \\
\text { Realizadas }\end{array}$ & $\begin{array}{c}\text { Número de } \\
\text { Encuestas } \\
\text { Respondidas }\end{array}$ & $\begin{array}{c}\text { Limite Inferior } \\
\text { Intervalo de } \\
\text { Confianza para } \\
\text { la Media al } \\
95 \%\end{array}$ & Media & $\begin{array}{c}\text { Limite Superior } \\
\text { Intervalo de } \\
\text { Confianza para la } \\
\text { Media al 95\% }\end{array}$ \\
\hline 176 & 176 & 51 & 54 & 58 \\
\hline
\end{tabular}

Fuente: elaboración propia a partir de los datos obtenidos

En la cuestión siguiente $\left(\mathrm{N}^{\circ} 6\right)$, se pregunta sobre si en la visita realizada se ofrecía una degustación. El $76 \%$ de los cuestionarios recogidos pone de manifiesto que sí realizaron degustaciones en buena parte de las visitas, bien en las visitas de profesionales o en las visitas de menor duración. En la siguiente tabla se aprecian todos los datos obtenidos.

Tabla 5. Degustaciones en Bodega

\begin{tabular}{|c|c|c|c|c|c|c|c|c|}
\hline $\begin{array}{l}\text { Respuest } \\
a\end{array}$ & $\begin{array}{c}\text { Tama } \\
\text { no de } \\
\text { la } \\
\text { muestr } \\
a\end{array}$ & $\begin{array}{c}\text { Número } \\
\text { de } \\
\text { sucesos }\end{array}$ & $\begin{array}{l}\text { Proporci } \\
\text { ón de la } \\
\text { muestra }\end{array}$ & \begin{tabular}{|} 
Estimación \\
de Wilson \\
para la \\
proporción de \\
la muestra
\end{tabular} & $\begin{array}{c}\text { Error } \\
\text { Standard } \\
\text { de la } \\
\text { Estimació } \\
n\end{array}$ & $\begin{array}{l}\text { Margen } \\
\text { de Error }\end{array}$ & $\begin{array}{c}\text { Limite } \\
\text { Inferior } \\
\text { para el } \\
\text { Intervalo } \\
\text { de } \\
\text { Confianz } \\
\text { a al } 95 \%\end{array}$ & \begin{tabular}{|c|} 
Limite \\
Superior \\
para el \\
Interval \\
o de \\
Confian \\
za al \\
$95 \%$
\end{tabular} \\
\hline$S i$ & 176 & 135 & 0,767 & 0,761 & 0,032 & 0,062 & 0,699 & 0,823 \\
\hline No & 176 & 41 & 0,233 & 0,239 & 0,032 & 0,062 & 0,177 & 0,301 \\
\hline
\end{tabular}

Fuente: elaboración propia a partir de los datos obtenidos

Incluso, en muchas ocasiones se realizaron degustaciones en bodegas en las que no se había cobrado tarifa de entrada. Un 24 \% no tuvieron degustación. 
En la pregunta No7, se planteaba la recomendación de llevar a cabo el sistema de tarifa por visitar una bodega. Esta pregunta resulta clave para el objeto de estudio, ya que actualmente muchas bodegas de la D.O. Ribera del Duero, no tienen programada ninguna gestión en la programación de tarifas de entrada y ningún tipo de organización al respecto. Son optimistas los resultados puesto que un $60 \%$ de la muestra, sí se muestra favorable a pagar una tarifa de entrada frente a un $40 \%$ que no lo está.

Las principales razones (un 60\%) que motivan a esta conducta de acceder a pagar una tarifa de entrada por visitar una bodega, es porque de este modo las bodegas no llegarían a masificarse. El público iría de forma más interesado y así, se procedería a una selección particular. Con una tarifa de pago, se frena el hecho de visitar una bodega sin interés y sin tener motivación.

Los que manifestaban una actitud contraria, un $40 \%$, era porque declaraban la suposición de una barrera para la promoción de las bodegas y de sus productos. De hecho, algunos de ellos coinciden en que sí se debiera establecer una tarifa para grupos numerosos (generalmente los que van a través de agencia o pertenecen a asociaciones públicas o privadas), pero hacerlas accesibles a todos los públicos sin pago de entrada.

Muchos de ellos opinan que el no establecer tarifa de entrada por acceder a visitar una bodega, se justifica con la posterior compra de vino en bodega (punto de venta de la bodega).

A continuación, se analizan los servicios que más se valoran a la hora de visitar una bodega por parte del turista. En la pregunta $\mathrm{N}^{\circ} 9$, se pretende conocer el servicio o novedad que se incluiría por parte del visitante para mejorar la atención en las visitas $\mathrm{y}$ resto de actividades en la bodega.

Uno de los servicios más valorados, es la atención profesional o grupo de personas del Departamento de Atención al cliente que realizan las visitas en la bodega. La dedicación de la persona que se encarga de la visita y la explicación es fundamental. Desean que se les aconseje y que se les resuelvan dudas y preguntas. Se muestran muy interesados por adquirir productos de venta en la bodega (ya sea el propio vino de la bodega o productos típicos de la comarca o región que también están a la venta en la propia bodega).

También solicitan y demandan nuevos servicios como la posibilidad de alojarse y poder comer en las instalaciones de la bodega.

Solicitan que la misma bodega les organice una visita turística por toda la zona, es decir, en ocasiones la bodega funciona como una auténtica oficina de turismo de la zona. 
Algunos de los turistas desean participar de las tareas de la bodega; como por ejemplo vendimiar en la época de recogida de la uva y comer con uno de los dueños de la misma.

En la segunda parte del cuestionario, a través de la pregunta $\mathrm{N}^{\circ} 1$, todos los encuestados se muestran interesados por visitar una bodega; es indudable que al efectuar esta pregunta en zonas de una región de gran tradición vitivinícola, todos se muestren interesados y contesten afirmativamente.

En la cuestión $\mathrm{N}^{\circ} 2$, los principales criterios que siguen para decidirse a visitar una bodega, son los de recomendación. Esto quiere decir que los visitantes han recibido alguna información previa de alguna bodega por parte de amigos, conocidos o familiares. Otorgan también mucha importancia a la calidad de los vinos que se elaboran o se distribuyen, así como la Denominación de Origen a la que pertenece la bodega y sus vinos. La pertenencia a una Denominación de Origen aporta un valor añadido al producto; es decir, gracias a este sello de calidad de origen y pertenencia, el consumidor consigue una seguridad de garantía y de exclusividad en beneficio del producto.

Tabla 6. Servicios que más se valoran a la hora de visitar una Bodega

\begin{tabular}{|c|c|c|c|c|c|c|c|c|}
\cline { 2 - 9 } \multicolumn{1}{c|}{ Cercanía } & Recomendación & Preferencia & Zona & Fama & Trato & Servicios & Gratuidad \\
\hline $\mathbf{1}$ & $3,5 \%$ & $43,1 \%$ & $35,9 \%$ & $12,6 \%$ & $12,1 \%$ & $15,0 \%$ & $1,7 \%$ & $1,9 \%$ \\
\hline $\mathbf{2}$ & $5,3 \%$ & $27,7 \%$ & $34,4 \%$ & $5,4 \%$ & $19,0 \%$ & $31,6 \%$ & $12,2 \%$ & $13,2 \%$ \\
\hline $\mathbf{3}$ & $\mathbf{1 9 , 3} \%$ & $9,2 \%$ & $10,2 \%$ & $21,6 \%$ & $32,8 \%$ & $21,1 \%$ & $15,7 \%$ & $17,0 \%$ \\
\hline $\mathbf{4}$ & $0,0 \%$ & $5,4 \%$ & $4,7 \%$ & $18,0 \%$ & $17,2 \%$ & $15,0 \%$ & $15,7 \%$ & $17,0 \%$ \\
\hline $\mathbf{5}$ & $10,5 \%$ & $5,4 \%$ & $3,1 \%$ & $9,0 \%$ & $9,5 \%$ & $7,5 \%$ & $22,6 \%$ & $24,5 \%$ \\
\hline $\mathbf{6}$ & $15,8 \%$ & $3,8 \%$ & $5,5 \%$ & $14,4 \%$ & $2,6 \%$ & $6,8 \%$ & $8,7 \%$ & $9,4 \%$ \\
\hline $\mathbf{7}$ & $\mathbf{1 0 , 5} \%$ & $4,6 \%$ & $3,9 \%$ & $12,6 \%$ & $2,6 \%$ & $1,5 \%$ & $19,1 \%$ & $20,8 \%$ \\
\hline $\mathbf{8}$ & $\mathbf{2 7 , 2} \%$ & $0,0 \%$ & $1,6 \%$ & $5,4 \%$ & $3,4 \%$ & $0,8 \%$ & $3,5 \%$ & $3,8 \%$ \\
\hline $\mathbf{9}$ & $0,0 \%$ & $0,0 \%$ & $0,0 \%$ & $0,0 \%$ & $3,4 \%$ & $0,0 \%$ & $0,0 \%$ & $0,0 \%$ \\
\hline
\end{tabular}

Fuente: elaboración propia a partir de los datos obtenidos

En la siguiente figura 2 se detallan de forma gráfica los resultados obtenidos en la tabla. Se observa que los criterios de recomendación, preferencia y fama son los aspectos más valorados y que más se tienen en cuenta para visitar una bodega. 


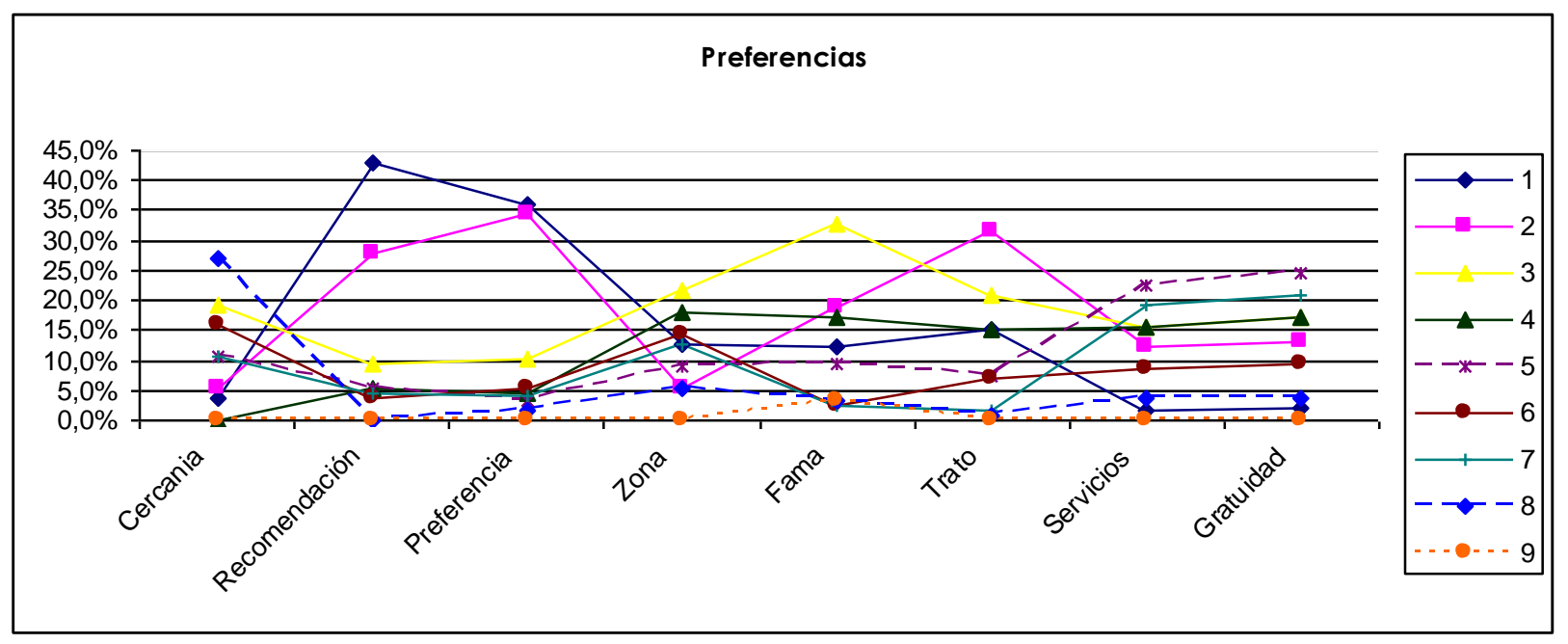

Figura 2.

Por último en cuarto puesto, se valora notablemente el trato personal que se ofrece en la bodega y los servicios de atención prestados durante la visita. Todo esto influirá para que siga la cadena de recomendaciones de unos clientes a otros, algo tan común y eficaz como es la técnica más popular de la comunicación y la publicidad: el boca a boca o boca oreja, ya comentado en capítulos anteriores. Se trata de una de las mejores armas de comunicación; vulgar, cotidiana y nada costosa que favorece la comunicación para un servicio o producto.

En la pregunta $\mathrm{N}^{03}$, se preguntaba por la frecuencia con que se visita una bodega. Esta frecuencia es muy diversa y varía bastante dependiendo de la época y el momento del año y día de la semana.

Casi un 32\% visita la bodega una vez al año, un 22,7\% realiza las visitas en vacaciones de verano y un 5,7\% una vez al mes; generalmente las visitas a bodegas suelen ser muy ocasionales. Las épocas preferidas son las de verano y primavera con un $44 \%$ y durante la época de vendimias.

Los días escogidos suelen ser los que coinciden con el fin de semana, normalmente sábados o días festivos. También en fiestas más prolongadas como las que coinciden en puentes. Esto es bastante comprensible, puesto que los visitantes suelen escoger aquellos días en los que no trabajan y descansan, pudiendo tener más tiempo para el ocio, el descanso y la diversión.

Se resalta la importancia de lo comentado anteriormente, ya que uno de los principales problemas que se ha detectado en la D.O. Ribera del Duero, es que no todas las bodegas abren sus puertas los fines de semana. Éste es un hecho a destacar y clave para la discusión. Para que el visitante tenga una buena imagen de la D.O. Ribera del Duero y repita su visita, es necesario que las bodegas del entorno no cierren sus instalaciones en fines de semana y fiestas. Es evidente que para adaptarse a esta situación el gerente de una bodega debe contemplar la posibilidad de ampliar el 
número de personas contratadas para estos días clave para el turismo de interior y turismo del vino.

En otra pregunta del segundo bloque se consultaba sobre el día de la semana que suele escoger el turista para visitar una bodega. De esta manera, pueden conocerse los días escogidos por el turista del vino para realizar alguna actividad enoturística. Dichos resultados pueden servir a los gestores y profesionales del enoturismo para programar las actividades y diversas promociones a lo largo de la semana.

Se obtiene un elevado porcentaje en la opción de Indiferente con un $44 \%$, siguiendo a este porcentaje con un $17 \%$ las visitas que suelen hacerse en fin de semana. Por tanto, se comprueba que no existe entre la muestra escogida un día determinado.

En posteriores preguntas se llega a la conclusión de que es la primavera (con un 43\%) y el verano (con un 22\%) las épocas preferidas por el turista del vino para desplazarse a las bodegas de la Ribera. No resulta de extrañar ya que es la época en la que el viñedo tiene su mayor esplendor. Además, se trata de épocas que coinciden con el inicio de las vacaciones para muchos clientes y turistas que aprovechan sus días libres para viajar.

La media de los días para visitar bodegas es de tres días y medio (3,5 días), siendo el máximo de una semana y el mínimo de un día. En la siguiente tabla 23 y siguientes figuras 26 y 27 se detallan los datos,

\section{Tabla 7. Media de días para visitar una bodega}

\begin{tabular}{|c|c|c|c|c|}
\hline & & \multicolumn{3}{|c|}{ Días } \\
\hline $\begin{array}{l}\text { Número de } \\
\text { Encuestas } \\
\text { Realizadas }\end{array}$ & $\begin{array}{l}\text { Número de } \\
\text { Encuestas } \\
\text { Respondidas }\end{array}$ & $\begin{array}{c}\text { Limite Inferior } \\
\text { Intervalo de } \\
\text { Confianza para la } \\
\text { Media al } 95 \%\end{array}$ & Media & $\begin{array}{l}\text { Limite Superior } \\
\text { Intervalo de } \\
\text { Confianza para la } \\
\text { Media al 95\% }\end{array}$ \\
\hline 176 & 53 & 2,36 & 3,51 & 3,64 \\
\hline
\end{tabular}

Fuente: elaboración propia a partir de los datos obtenidos

Se puede apreciar que hay encuestados que pueden estar visitando bodegas desde un día (límite mínimo alcanzado) hasta ocho días (valor o límite máximo). El diagrama de caja muestra como la media $(3,51)$ y la mediana (3) resultante están muy próximas. Se trata de una distribución asimétrica positiva ya que los datos se extienden más hacia la derecha y el valor de la media está por encima de la mediana. La media obtenida está más cerca del primer cuartil Q1 (que es 2), mientras que el tercer cuartil Q3 (6) está más alejado.

En la pregunta $\left(\mathrm{N}^{\circ} 9\right)$, se formula una cuestión abierta en la que se pregunta sobre si se detectaban anomalías en las visitas a las bodegas. De este modo, también se solicita que se indiquen cuáles son las razones. En este aspecto, no se ha apreciado ninguna 
anomalía. En general, la gran mayoría quedaron satisfechos salvo en algunos casos que en el que la visita les pareció corta y poco profesional.

A partir de la pregunta $\mathrm{N}^{\circ} 10$, se valoran las preguntas que determinan y ponen de manifiesto la utilidad del método de valoración contingente; se puede decir que el 56\% de las respuestas son afirmativas sobre la disposición a pagar $6.00 €$ por visitar una bodega y degustar uno de sus vinos. El otro $44 \%$ opina lo contrario, es decir no pagaría esta cantidad por una visita y degustación.

Tabla 8. Número de personas dispuestas a pagar $6.00 €$

\begin{tabular}{|l|r|r|r|r|r|}
\hline Hasta $6.00 €$ & $600-1500 €$ & $1501-2500 €$ & $2501-3500 €$ & $3501-5000 €$ & Más de 5000€ \\
\hline Si & 18 & 43 & 25 & 6 & 7 \\
\hline No & 46 & 6 & 14 & 4 & 5 \\
\hline
\end{tabular}

Fuente: elaboración propia a partir de los datos obtenidos

Tabla 9. Tarifa de 3.00 Euros por sólo visitar la Bodega

\begin{tabular}{|l|r|r|r|r|r|r|r|r|}
\hline $\begin{array}{l}\text { Respues } \\
t a\end{array}$ & $\begin{array}{c}\text { Tamaño } \\
\text { de la } \\
\text { muestra }\end{array}$ & $\begin{array}{c}\text { Número } \\
\text { de } \\
\text { sucesos }\end{array}$ & $\begin{array}{c}\text { Proporción } \\
\text { nde la } \\
\text { muestra }\end{array}$ & $\begin{array}{c}\text { Estimación } \\
\text { de Wilson } \\
\text { para la } \\
\text { proporción } \\
\text { de la } \\
\text { muestra }\end{array}$ & $\begin{array}{c}\text { Error } \\
\text { Standard de } \\
\text { la } \\
\text { Estimación }\end{array}$ & $\begin{array}{c}\text { Margen de } \\
\text { Error }\end{array}$ & $\begin{array}{c}\text { Limite } \\
\text { Inferior } \\
\text { para el } \\
\text { Intervalo de } \\
\text { Confianza } \\
\text { al 95\% }\end{array}$ & $\begin{array}{c}\text { Superior } \\
\text { para el } \\
\text { Intervalo de } \\
\text { Confianza } \\
\text { al 95\% }\end{array}$ \\
\hline Si & 176 & 105 & 0,597 & $\mathbf{0 , 5 9 4}$ & 0,037 & 0,072 & 0,523 & 0,666 \\
\hline No & 176 & 71 & 0,403 & $\mathbf{0 , 4 0 6}$ & 0,037 & 0,072 & 0,334 & 0,477 \\
\hline
\end{tabular}

Fuente: elaboración propia a partir de los datos obtenidos

En el momento de decidir un valor para el menú degustado en bodega (pregunta $\mathrm{N}^{\circ} 12$ ) la visita de la misma y la cata de alguno de los vinos; un 44,3\% está dispuesto a pagar como máximo $30 €$ por todo el servicio incluido, un $17 \%$ hasta $40 €$, un $10,2 \% 50$ $€$ y un $2,3 \%$ hasta $60 €$, un 1,1\% estaría dispuesta a pagar más de esta última cantidad. El $25 \%$ pagaría menos de $30 €$ por todo el servicio.

Tabla 10. Tarifa Completa: Visita, Degustación y Comida en Bodega. Menos de $30.00 € /$ hasta $30.00 €$ / hasta $40.00 €$ / hasta $50.00 €$ / hasta $60.00 €$

\begin{tabular}{|c|c|c|c|}
\hline Respuesta & Tamaño de la muestra & $\begin{array}{c}\text { Número de } \\
\text { sucesos }\end{array}$ & $\begin{array}{c}\text { Proporción de la } \\
\text { muestra }\end{array}$ \\
\hline Menos 30€ & 176 & 44 & $\mathbf{0 , 2 5 0}$ \\
\hline $30 €$ & 176 & 78 & $\mathbf{0 , 4 4 3}$ \\
\hline
\end{tabular}




\begin{tabular}{|c|c|c|c|}
\hline $\mathbf{4 0 €}$ & 176 & 30 & $\mathbf{0 , 1 7 0}$ \\
\hline $\mathbf{5 0 €}$ & 176 & 18 & $\mathbf{0 , 1 0 2}$ \\
\hline $\mathbf{6 0 €}$ & 176 & 4 & $\mathbf{0 , 0 2 3}$ \\
\hline Más $\mathbf{6 0} €$ & 176 & 2 & $\mathbf{0 , 0 1 1}$ \\
\hline
\end{tabular}

Fuente: elaboración propia a partir de los datos obtenidos

Se observa que la tarifa más demanda y aplaudida por los encuestados es la de $30.00 €$, independientemente de los ingresos que se tengan. En este caso, se concluye que por los servicios de visita, degustación de un vino y comida en las instalaciones, los encuestados pagarían hasta $30.00 €$ y en menor medida hasta $40.00 €$ aquéllos que cuentan con unos ingresos de 2501 y $3500 €$.

Las última pregunta de la segunda parte, pregunta $\mathrm{N}^{\circ} 13$, se trata de una pregunta dicotómica y de recuerdo de la primera parte del cuestionario.

En esta última cuestión, la mayoría de los encuestados con un $80 \%$ han quedado satisfechos en las visitas en las que tenían que pagar por sólo ver la bodega frente a un $20 \%$ que opinó lo contrario; en este último caso, pensaron que la visita fue demasiada corta.

En la última parte del cuestionario, en las preguntas sociodemográficas de la tercera parte, del total de la muestra recogida se comprueba que la edad media de los encuestados es de 42 años. Los cuestionarios se realizaron a personas con edades comprendidas entre los 19 años y 80 años

Respecto a la distinción de género, se ha establecido un equilibrio ya que un $51 \%$ han sido hombres y un $49 \%$ mujeres. No se han detectado grandes variaciones $y$ diferencias de respuesta en cuanto a la valoración del variable sexo.

Existe un porcentaje más alto de personas con estudios universitarios (el $49 \%$ ) casi el $50 \%$ y secundarios (con un $46 \%$ ) que con estudios primarios $(4,5 \%$ ).

Se ha distinguido (Figura 3) que las personas con más alto nivel de estudios valoran más el servicio profesional y las explicaciones técnicas de las catas y visitas en las bodegas. Éstos están dispuestos a pagar un precio mayor por todos los servicios en general y a establecer una tarifa de entrada por visitar la bodega, bien con degustación o sin ella. 
Figura 3.

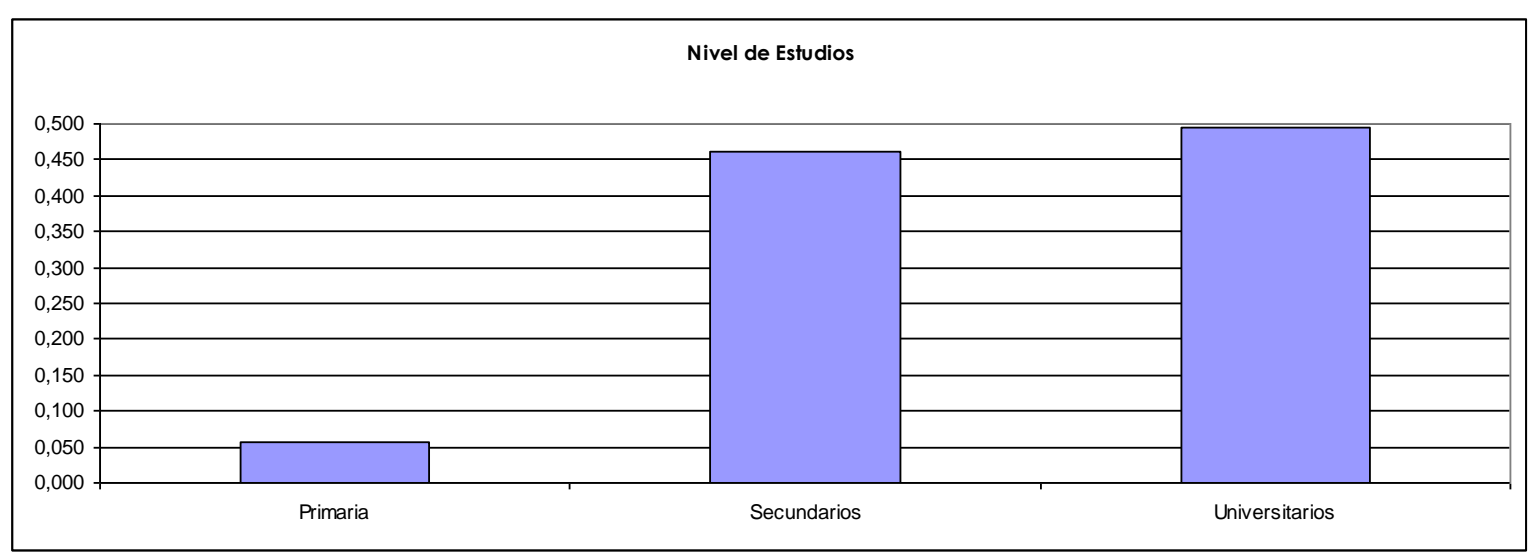

Fuente: elaboración propia a partir de los datos obtenidos

Tabla 11. Ingresos Mensuales brutos por Unidad familiar: 600-1500 $€$ / 1501-2500 $€$ / 2501-3500€/3501-5000€/ Más de 5001€

\begin{tabular}{|l|r|r|r|}
\hline Respuesta & Tamaño de la muestra & Número de sucesos & $\begin{array}{c}\text { Proporción de la } \\
\text { muestra }\end{array}$ \\
\hline $600-1500 €$ & 176 & 64 & $\mathbf{0 , 3 6 4}$ \\
\hline $1501-2500 €$ & 176 & 49 & $\mathbf{0 , 2 7 8}$ \\
\hline $2501-3500 €$ & 176 & 39 & $\mathbf{0 , 2 2 2}$ \\
\hline $3501-5000 €$ & 176 & 10 & $\mathbf{0 , 0 5 7}$ \\
\hline Más de 5001 & 176 & 12 & $\mathbf{0 , 0 6 8}$ \\
\hline Estudiante & 176 & 0 & $\mathbf{0 , 0 0 0}$ \\
\hline No trabaja & 176 & 2 & $\mathbf{0 , 0 1 1}$ \\
\hline
\end{tabular}

Fuente: elaboración propia a partir de los datos obtenidos

Muchos de los encuestados, un $64 \%$ pertenecen a un status socioeconómico medio, se mueven en cifras entre los $1.000 €$ y $\operatorname{los} 2.500 €$ de ganancias mensuales por unidad familiar ${ }^{14}$. De los encuestados ninguno se encontraba en situación de paro. Un $1 \%$ no trabajaba. No se encontró entre la muestra a ningún estudiante. Tan sólo un 5\% ganaba entre los $3.500 €$ y los $5.000 €$. Casi un $7 \%$ de los encuestados ganaba por encima de los $5.000 €$.

En cuanto a los resultados sobre el número de miembros pertenecientes a la unidad familiar, se destacan los siguientes datos:

\footnotetext{
${ }^{14}$ Ingresos globales de toda la familia.
} 
La media de miembros por unidad familiar es de 3 personas. Se trata de una distribución de tipo simétrica ya que la media y la mediana coinciden.

El 97\% de los encuestados no pertenecen a ninguna asociación de sumilleres o de vino. Un 3\% tienen tarjetas de fidelización por la compra de vino en alguna bodega, pero no pertenecen a ningún tipo de asociación del vino.

Finalmente se muestra en la siguiente tabla el origen de procedencia de los turistas del vino.

Tabla 12. Procedencia del Turista

\begin{tabular}{|l|r|r|r|r|}
\cline { 2 - 5 } \multicolumn{1}{l|}{} & $\begin{array}{l}\text { Castilla y } \\
\text { León }\end{array}$ & Madrid & Extranjero & Otros \\
\hline Porcentajes \% & $37 \%$ & $46 \%$ & $11 \%$ & $6 \%$ \\
\hline
\end{tabular}

Fuente: elaboración propia a partir de los datos obtenidos

\section{CONCLUSIONES}

El enoturismo o turismo enológico es aquel tipo de turismo dedicado a gestionar y potenciar la riqueza vitivinícola, está vinculado a conocer bodegas, la historia y saborear los vinos de la región. Los turistas conocen cada zona vitivinícola a través de la degustación de sus vinos y la visita a bodegas y viñedos. Esta situación conlleva la aparición de un nuevo turismo desconocido hasta hace unos años para algunos, pero cada vez más importante para otros.

Es evidente que cada vez se afianza más el concepto de Enoturismo. El turista no muestra el mismo interés por planificar los ya conocidos viajes a la costa y a las zonas turísticas masificadas. Los turistas demandan viajes más selectivos y a la carta, es decir, desean servicios más especializados y personalizados, quieren acceder a lo más selecto y minoritario como si fuera un símbolo de distinción.

En definitiva, si se reflexiona sobre cuál es el tipo de cultura que impera en España, es lógico pensar que este fenómeno enoturístico tenga más desarrollo y acogida en países como éste (cultura mediterránea). En una ocasión, Pérez-Reverte (2007), definió la cultura española como el arte de saber disfrutar el día a día, dentro de un entorno de convivencia y de referencia social y cultural.

El hombre necesita socializarse y descubrir su entorno, su naturaleza y conocer todo lo que le rodea. Lo nuevo y diferente resulta mucho más atractivo. Y por ello, muchos visitantes venidos desde el extranjero muestran un gran interés por la cultura española (Elías, 2005: 78). 
En el cuestionario, se observa como la mayoría de los turistas valoran de forma destacada las recomendaciones de amigos, familiares o conocidos que les han sugerido o recomendado una bodega que finalmente han visitado; su paisaje, el vino que han catado y comprado y el restaurante donde han comido. Esto hace que bien por curiosidad, interés o disfrute de una experiencia propia, sean motivos suficientes para hacer la visita merecida y proseguir con el boca a boca de la visita a una bodega y de una región vitivinícola concreta.

Muchos de los encuestados, sí estarían dispuestos a pagar una tarifa de entrada. Incluso de hasta $10.00 €$, si se les atiende profesionalmente y si se incluye algún tipo de degustación.

Con el método de Valoración Contingente se puede saber que pagarían hasta $30.00 €$ por un servicio completo de visita, degustación y comida. Algunos pagarían cantidades de $40.00 €$, pero en menor medida. El hecho de que las familias dispongan de mayor liquidez y salario no hace variar sus respuestas, ya que existen unidades familiares que ganan más de $4.000 €$ mensuales (con tan sólo 3 miembros en el hogar familiar) y que pagarían hasta $30.00 €$ o una cantidad de $40.00 €$ como máximo.

En cambio, se detecta una relación más directa entre los que obtienen más ingresos por unidad familiar y los que estarían dispuestos a pagar por una tarifa de entrada para visitar sólo las instalaciones de la bodega. Éstos estarían dispuestos a pagar incluso una tarifa superior a la de $6.00 €$ por persona. Con este hecho, se justifica también que tienen el derecho de contar con un guía adecuado que les explique el recorrido de la visita y resuelva sus dudas e inquietudes.

Es también más frecuente que las personas con estudios universitarios valoren y tengan más en cuenta las visitas profesionales y técnicas. En estas visitas, por ejemplo, quieren aprender y conocer el desarrollo de la cultura del vino, cómo se elabora el vino y el funcionamiento de este mercado. Además, suelen realizar bastantes preguntas y se muestran muy interesados en el tema (a pesar de no ser profesionales). Respondiendo a los objetivos marcados, se puede concluir con las siguientes apreciaciones que se han obtenido a partir de la realización de este cuestionario descriptivo:

Un 56\% sí pagaría un máximo de $6.00 €$ por visitar y degustar uno de los vinos de la bodega, frente a un $44 \%$ que no lo haría.

Un 59\% pagaría $3.00 €$ por visitar sólo la bodega sin degustación frente a un $41 \%$ que no lo haría.

Por el servicio completo (visita, degustación y comida) un $64 \%$ pagaría hasta $30 €$, un $17 \%$ hasta $40.00 €$ y un $10 \%, 50.00 €$.

El estereotipo de visitante de una bodega de la D.O. Ribera del Duero, es aquel hombre o mujer de 42 años principalmente. No estrictamente profesional. Conocedor 
y amante de vinos con un grado de conocimiento de ligero a medio (aunque existen visitas de profesionales). Con un nivel de estudios medios y universitarios, de clase media y media alta, pertenecientes a familias no numerosas ( 3 o 5 personas como máximo en total) procedente de Castilla y León y Madrid fundamentalmente.

Demandan una dedicación profesional y amable por parte del guía que enseña y atiende en las instalaciones de la bodega. Solicitan la degustación de varias marcas de vinos y de productos de la zona y la atención personalizada para completar su viaje o visita por la Denominación de Origen de vinos en la que se encuentran. Demandan calidad en todos los servicios de los que se pueda disfrutar en la bodega.

El futuro ya no es elaborar únicamente vinos, sino el disfrutar y pasar varios días en la propia bodega; Conocer el entorno, degustar y catar los vinos, probar la comida de la zona, alojarse en la bodega, catar diferentes marcas y descubrir el viñedo pisando la tierra que ha visto crecer las cepas y los racimos que cuelgan de sus brazos, vendimiar y participar de las tareas de la bodega, descubrir en definitiva, la cultura del vino y poder vivirla para después poder transmitirla.

\section{REFERENCIAS}

Barreiro, J. y Pérez, L. (1997): “Efecto del formato de pregunta en valoración de bienes públicos a través del método de valoración contingente". Hacienda Pública Española, No143 (4), pp. 107-121.

Burgos, D. y León, L. (2001): Comercio electrónico, publicidad y marketing en Internet. Madrid. Esic.

Carson, R.; Wright, J.; Alberinbi, A. y Flores, N. (1995): A bibliography of Contingent Valuation studies and papers. Natural Resource Damages Assexment Inc. La Jolla. California.

Crompton, J. L. (1979): “Motivations of pleasure vacation”. Annals of Tourism Research, 6, 408-424. id. McGraw - Hill. London.

Dann, G. M. (1981): “Tourism Motivations: An appraisal”. Annals of Tourism Research, 8(2), 189-219. London.

Del Rey, R. (2010): El Enoturismo y sus estrategias. Madrid. Ra-Ma Editorial.

Elías, L.V. (2005): El turismo del Vino. Otra experiencia de Ocio. Bilbao. Ediciones Deusto.

Gómez, A. (2006): Marketing relacional directo e interactivo. Madrid. Ra-Ma Editorial.

Pérez Reverte, A. (2007): “Patriotas de Cercanías". XLSemanal. No1.042 (14-20 octubre), [Editado por Taller de Editores], p. 8. 


\subsection{Documentos electrónicos.}

"Actividades enológicas llevadas a cabo por la diputación" (2011). Extraída el 24/III/2012. Diputación Provincial de Valladolid.

http://www.diputaciondevalladolid.es

Guía del turismo del vino en España 2007. Barcelona: Anaya Touring Club.

“El Bus Vino recorre viñedos de Toro, Urueña y Montealegre". (2011). El Norte de Castilla. Valladolid. Extraída el 02/04/2011.

http:/ / www.elnortedecastilla.es/v/20110129/valladolid/vino-recorrera-vinedos toro-20110129.html.

"Situación de los vinos con denominación de origen de Castilla y León". (2011). Junta de Castilla y León. Agricultura y ganadería. Extraída el 03/03/2011

www.jcyl.es/web/jcyl/AgriculturaGanaderia/es/Plantilla100Detalle/1246464862173 /_/1272896477299/Comunicacion?plantillaObligatoria=PlantillaContenidoNoticiaHo me

Página Web de Grupo Matarromera: $\underline{\text { www.emina.es }}$

Página Web de Bodegas Hnos. Pérez Pascuas: www.perezpascuas.com

Página Web de Castilla y León de Vinos: www.castillayleondevinos.com

Enlace de bodegas del Consejo Regulador D.O. Ribera del Duero:

http://www.riberadelduero.es/web/bodegas/bodegas.asp

Página Web del Centro del Vino de Aranda de Duero: www.arandacentrodelvino.com

\section{Mónica Matellanes-Lazo}

Licenciada (2001) en Publicidad y RR.PP. por la Universidad Complutense de Madrid y Doctora (2009) por la Universidad de Valladolid en Comunicación del Enoturismo.

Ha trabajado en Comunicación y Marketing dentro del área vitivinícola y actualmente es profesora agregada en Comunicación y Marketing en la Universidad Europea Miguel de Cervantes de Valladolid. Varias veces profesor Erasmus y congresista en Universidades extranjeras de Portugal (Lisboa, Ponte de Lima) y en Reino Unido (Aberystwyth). Autor de varios artículos de investigación en el área de Comunicación y la Web 2.0, últimas apariciones en Marketing y Ventas, Vivat Academia, Revista Deusto \& Harvard, Razón y Palabra. 